\title{
Defining Nature-Based Solutions Within the Blue Economy: The Example of Aquaculture
}

\section{OPEN ACCESS}

Edited by:

Tomaso Fortibuoni,

Istituto Superiore per la Protezione e la Ricerca Ambientale (ISPRA), Italy

Reviewed by:

Robin Kundis Craig,

The University of Utah, United States

Daniele Brigolin,

Università luav di Venezia, Italy

Raphaëla Le Gouvello,

STERMOR Ocean and Coastal

Sustainability, France

*Correspondence:

Adam D. Hughes

adam.hughes@sams.ac.uk

Specialty section:

This article was submitted to

Marine Fisheries, Aquaculture and Living Resources,

a section of the journal

Frontiers in Marine Science

Received: 18 May 2021

Accepted: 09 July 2021

Published: 29 July 2021

Citation:

Hughes AD (2021) Defining Nature-Based Solutions Within the Blue Economy: The Example

of Aquaculture.

Front. Mar. Sci. 8:711443.

doi: 10.3389/fmars.2021.711443

\section{Adam D. Hughes* \\ Scottish Association for Marine Science, Oban, United Kingdom}

The concepts of Nature-based Solutions ( $\mathrm{NbS}$ ) and the Blue Economy (BE) are two prominent sustainability frameworks at the forefront of policy dialogues. However, investment within the BE has been slowed by the lack of a sufficiently robust operational definition. This lack of definition reduces investor confidence and impacts adoption by policy makers and practitioners. By considering the overlap between the two sustainability frameworks it is possible to identify specific sectors and activities within the BE that also fit the operationalised criteria for NbS. Undertaking this process for one sector of the BE (aquaculture) has provided evidence that aquaculture activities, if planned and operated within the criteria, would qualify as NbS and as such may unlock financing for the provision of ecosystem services.

Keywords: sustainability, low trophic level aquaculture, IMTA (integrated multi-trophic aquaculture), NBS, blue growth, ocean economy, ecosystem approach to aquaculture (EAA)

\section{INTRODUCTION}

As our understanding of the impacts that human economic activity has on the environment increases, a number of frameworks have been developed and utilised to contextualise, measure and ultimately manage these impacts. In a western context this thinking can be traced back to the 18th Century and earlier (Du Pisani, 2006), with links made more recently between economic and ecological equilibrium and sustainable economic growth (Meadows et al., 1972) and with key milestones such as Rio 1992 and the millennium ecosystem assessment (Reid et al., 2005). One such framework is that of Nature-based Solutions (NbS) which signposted a shift in thinking from conserving nature for its own sake to conserving for peoples sake (Seddon et al., 2021) and sits within a wider stable of concepts that can be termed the green economy (Loiseau et al., 2016). This concept of NbS and its subsequent framework has grown out of a term first used, but not defined, in a world bank report of 2008 titled "Biodiversity, Climate Change, and Adaptation: Nature-based Solutions from the World Bank Portfolio" (MacKinnon et al., 2008). The report detailed strategies for the management and adaptation to climate change and biodiversity loss that were based in the concepts of ecosystem management and conservation. The term was further defined in 2009 by explicitly making the link between biodiversity and ecosystem management and human economic 
development through forests, fisheries and agriculture (MacKinnon and Hickey, 2009); also the role these can play in carbon sequestration. In the same year an IUCN position paper to COP15 endorsed NbS for climate change to "harness the potential of healthy and well managed ecosystems to build resilience and reduce the vulnerability of people to the impacts of climate change" (Parker, 2009). Subsequently the term was adopted by the IUCN as one of three areas in its 2012-2016 work program (Cohen-Shacham et al., 2016). The IUCN adopted the definition of $\mathrm{NbS}$ as "actions to protect, sustainably manage, and restore natural or modified ecosystems, that address societal challenges effectively and adaptively, simultaneously providing human well-being and biodiversity benefits." Importantly this definition builds on the concept in three important aspects. Firstly, it expands the concept of NbS from ecosystem management and conservation to include not just natural ecosystems but also to modified ecosystems. This links to the 2009 framing of the term that included forests, agriculture and fisheries, but significantly expands the scope into the framework of social ecological systems (SES; Berkes et al., 2000). Secondly it also expands the desired outcomes from focussing on climate change resilience to a broader category of societal need and from poverty alleviation to human well-being. Thirdly it explicitly recognises the NbS' needs to deliver both ecological and social benefits. The IUCN definition was further developed and effectively operationalised through the development of a typology that categorised NbS into three main groupings along two orthogonal axes (Eggermont et al., 2015): firstly the degree of engineering of the ecosystem that is undertaken and the second axis being the number of ecosystem services (ES) and stakeholder groups targeted. This ordination reveals three main typologies, of which Type 3 which is the furthest along both of these axes and is described as follows: "consists of managing ecosystems in very intrusive ways or even creating new ecosystems (e.g., artificial ecosystems with new assemblages of organism)." The authors recognise that in some cases this typology moves the definition beyond the IUCN definition and caveats that for all cases, NbS should contribute to preserving biodiversity and restoring ecosystems while delivering a range of ES.

\section{POLICY OPTIONS AND IMPLICATIONS}

This development of the definition and steps toward the operationalisation of the NbS concept clearly demonstrates a strong link or nexus between NbS, ES (Almenar et al., 2021) and the context and sector specific challenges that are being addressed. However, the concept is still open and loosely defined (Randone et al., 2017), and this can represent a barrier to practitioners and policy makers in the adoption and application of the concept (Maes and Jacobs, 2017; Almenar et al., 2021). But the use of ES and an understanding of the specific context allows the anchoring of $\mathrm{NbS}$ within existing SES frameworks (Shah et al., 2020). These frameworks are crucial where there is a need to take the expanding ES literature and to use it as the catalyst for an action situation (Rodríguez-Robayo and Merino-Perez, 2017; sensu Ostrom) that leads to the benefits ascribed to the NbS approach. This anchoring allows both the recognition that any $\mathrm{NbS}$ is embedded in a complex web of interactions, subsystems, and internal variables (Ostrom, 2009) and that practitioners and policy makers can use existing SES frameworks to operationalise the concept. This operationalisation is key for the marine environment where inadequate frameworks and taxonomies have been highlighted as a principle barrier to sustainable financing and investment in Sustainable Ocean Economy or the Blue Economy (BE; Sumaila et al., 2020).

The concept of the $\mathrm{BE}$ as it relates to the sustainable development of coastal countries came out of the preparatory discussions for the Rio+20 conferences which were held in Rio de Janeiro in 2012. The concept of greening the BE was introduced at a meeting in Paris titled "A Blueprint for Ocean and Coastal Sustainability” (IOC/UNESCO et al., 2011). This meeting recognised the use of ocean space and resources as an essential component of global economic growth and prosperity and used the term "Blue-Green" Economy to refer to the transition to a human-ocean centred relationship of living with and from the oceans in a sustainable way. This meeting and the subsequent report highlighted the role of several key industries in this development. At the core of the BE concept is the de-coupling of socio-economic development from environmental degradation. It breaks the mould of the business as usual "brown" development model where the oceans have been perceived as a relatively unregulated source of resources and a waste dumping location with costs, financial and environmental, generally externalised from economic calculation. A robust definition of the "Blue Economy" is proving challenging to establish, with different stakeholders using it to cover wide ranging aspects of sustainable development in the context of utilising marine resources: fish, energy, mineral, transport, tourism, biotechnology, and others. However, the concept carries much political weight having been widely adopted by a large number of Governments and NonGovernmental Organisations including the United Nations, the World Bank (Bank et al., 2017), the Asian Development Bank, and WWF. Along with this recognition there have been a number of attempts at valuing the "economy" of our seas. An OECD report in 2017 valued the Ocean Economy at \$1.5 trillion as of 2010 (Cervigni and Scandizzo, 2017), while other estimates of Gross Marine Product place the value at \$2.5T (HoeghGuldberg, 2015). Despite this value there is a recognised lack of investment within the sector and a lack of capital flowing toward the BE (REUTERS, 2020), and there are also recognised information gaps in level of financial investment in the $\mathrm{BE}$ The Organisation for Economic Co-operation and Development (OECD) estimated that official development assistance leveraged a total of $\$ 2.96$ billion of private finance between 2013 and 2017 (Whisnant and Vandeweerd, 2019; OECD, 2020). In addition the OECD recognised the lack of marine focus in the rapidly increasing Environmental, Social and Governance (ESG) investing, and cites the variety of standards and methodologies as challenging investor confidence in this sector. One of the barriers to investment in the BE, cited by $39 \%$ of asset managers, was a lack of definition of the BE (Suisse, 2020). The United Nations Environment Program Finance Initiative through the Sustainable Blue Economy Finance Initiative has recognised the 
TABLE 1 | The eight criteria as developed by the IUCN global standard for Nature-based Solutions (IUCN, 2020) and evidence to demonstrate how specific, planned aquaculture activities meet the criteria.

\section{Criteria}

NbS effectively address societal challenges

Design of NbS is informed by scale

NbS result in a net gain to biodiversity and ecosystem integrity

NbS are economically viable

NbS are based on inclusive, transparent, and empowering governance processes

NbS equitably balance trade-offs between achievement of their primary goal(s) and the continued provision of multiple benefits

NbS are managed adaptively, based on evidence

NbS are sustainable and mainstreamed within an appropriate jurisdictional context

\section{Evidence that aquaculture operations can meet the criteria}

Although aquaculture is principally concerned with the production of food (food security) it can be designed to meet other societal challenges such as climate change mitigation (Sondak et al., 2017), adaption (Galappaththi et al., 2020), economic and social development (Ponte et al., 2014), and the mitigation of environmental and biodiversity degradation (Lacoste et al., 2020).

Aquaculture development is a commonly licenced activity with that licence pertaining to a single spatial location, although the granting of licences often draws on considerations at a larger geographical scale (Hishamunda et al., 2014). As such aquaculture developments are often considered within a large seascape planning context. However, extending this to an integrated framework of marine spatial planning can identify further opportunities to increase food production, to reduce environmental harm (Lester et al., 2018) and to allow integration with other sectors (Abhinav et al., 2020).

The nature of the environmental impact of aquaculture is dependent on a range of factors including the scale, the type of organism cultured and the receiving environment (Ahmed and Thompson, 2019). However, aquaculture operations can be specifically designed to deliver conservation goals (Froehlich et al., 2017) and to provide an increase in regulating ecosystem services such as nutrient cycling and carbon storage in low trophic aquaculture such as shellfish or seaweed production. Furthermore aquaculture sites can, if designed appropriately, provide habitats and positively impact on biodiversity locally and at a regional scale (Gentry et al., 2020).

Although growth rates of the aquaculture industry have slowed since the 1980s and 1990s, they remain high (4.5\% between 2011 and 2018) and aquaculture now has a farm gate value of $\$ 263 \mathrm{~B}(\mathrm{FAO}, 2020)$. Within these figures there are significant differences between the economic viability, and this variability is context specific. However, there is a general negative relationship between sustainability and unit value of aquaculture (Neori and Nobre, 2012) reflecting possible trade-offs between sustainability and profitability for any aquaculture NbS. Furthermore, business models in aquaculture are often weighted toward economic rather than social development (Kaminski et al., 2020).

At a global level aquaculture exhibits a wide range of governance structures and processes. Much of this governance is based at the farm leve and has a focus on environmental regulation (Bush et al., 2019). There is, however, significant opportunity within the aquaculture industry and its associated governance to address issues of human rights and gender equality (Gopal et al., 2020; Graham and D'Andrea, 2021), community well-being (Campbell et al., 2021), and stakeholder intervention (Krause et al., 2020).

Constraints within complex systems makes trade-offs inevitable and the equitability of those trade-offs is dependent on how decisions are made (Sowell, 2019). Within aquaculture, trade-offs can be broadly distributed amongst the multiple pillars of sustainability (Valenti et al., 2018) and a number of tools have been developed to manage these trade-offs (Gimpel et al., 2018; Bohnes et al., 2019).

Although there is no systemic review of the philosophical basis to aquaculture governance and management, there is a body of evidence to demonstrate the application and value of adaptive management to the aquaculture sector (Fang et al., 2016; Craig, 2019) and clear frameworks for their future application (Doremus et al., 2011).

As previously discussed, aquaculture development already exists within comprehensive governance structures, policy frameworks and regulatory environments. However, their inclusion within the NbS framework would require an additional transparency in terms of design, implementation and lessons learnt to allow the effective scaling and persistence of the solution. This type of activity has already been implemented within the aquaculture sector, connected to technology or diffusion of more sustainable practices (Lebel et al., 2016; Alexander and Hughes, 2017). 
importance of finance to the development of the sustainable BE. It has highlighted a wide range of public and private investment initiatives within the $\mathrm{BE}$, and within this current investment landscape, financial services within the Seafood sector (including aquaculture) were prominent, although climate change and ecosystem service loss dominated the identified non-financial risks to investment. Conversely climate resilience and capturing positive environmental impact were the dominant non-financial considerations for financial institutions to engage with the sustainable BE (UNEP, 2021). Defining Nature based Solutions within the $\mathrm{BE}$ is a mechanism both to boost the investment within this sector of the economy and to mitigate some of the risks to investment that relate to a lack of definition.

There are strong linkages between the development of the concepts that underlie both the BE and the Nature Based Solutions framework and the development of the definitions, typologies and standards for $\mathrm{NbS}$ are transferable to the marine environment (IUCN, 2020) and its application in the marine environment has been particularly prevalent in the area of flood management and coastal defence (Inácio et al., 2020). The IUCN global standard for NBS lays out eight criteria based on the premise that an ecosystem-based approach can be used to manage functioning ecosystems and their natural resources as well as deliver solutions to societal needs, increasing both human wellbeing and biodiversity benefits. Using this premise, it is clear that some sectors of the BE using the European Union typology (European Commission, 2020) fall outside the framework of NbS, such as off shore renewables and shipping, whilst sectors such as aquaculture, fishing and coastal tourism have the capacity to fit within the NbS framework. Whilst not all activities within these sectors will fit the criteria for NbS, those that do have the potential to benefit from increased investment from private and public finance, and to receive better recognition of their benefit from policy makers and regulators.

\section{ACTIONABLE RECOMMENDATIONS: AQUACULTURE AS AN EXAMPLE OF NbS WITHIN THE BLUE ECONOMY}

Aquaculture is widely accepted as one of the pillars of the BE (Wenhai et al., 2019) and as an industry has a farmgate value of $\$ 263.6$ billion (FAO, 2020). Aquaculture can be broadly divided into two categories, those that rely on the addition of feed to the production system (fed aquaculture) and those which rely on the wider ecosystem to provide nutrients and energy (extractive aquaculture; Troell et al., 2009). In general, extractive aquaculture concerns the cultivation of low trophic species such as photoautotrophs and filter feeding animals. The impacts of these two types of aquaculture on ES are generally accepted to be functionally different (Alleway et al., 2019). The definitions of $\mathrm{NbS}$ are based around taking an ecosystem based approach to manage a functioning ecosystem, where the managed activities enhance ES by delivering benefits that both enhance human wellbeing and reduce ecosystem degradation. The concept of taking an ecosystem approach to aquaculture (EAA) management is already well developed (Soto et al., 2007).
It strives to balance diverse societal objectives by taking account of the knowledge and uncertainties of biotic, abiotic and human components of ecosystems (including their interactions, flows and processes) and applying an integrated approach within ecologically and operationally meaningful boundaries (FAO, 2005). This EAA has gained recognition, been widely adopted and has been linked to the development of aquaculture within the BE (Brugère et al., 2019). The first two principals of the EAA clearly link to the NbS approach, through ES and human well-being.

1. Aquaculture should be developed in the context of ecosystem functions and services (including biodiversity) with no degradation of these beyond their resilience capacity,

2. Aquaculture should improve human well-being and equity for all relevant stakeholders,

3. Aquaculture should be developed within the context of (and integrated with) other relevant sectors.

Not all aquaculture activity takes an EEA and not all aquaculture activity can offer $\mathrm{NbS}$ to the seven societal challenges the IUCN identify. The principles of NbS are wider than those of EAA, but an Ecosystem Approach to resource management does cover five of the eight principles of the NbS (Cohen-Shacham et al., 2019). In the IUCN global standard (IUCN, 2020) it is clear that to be classified a NbS, the activity must deliver human wellbeing, biodiversity and climate benefits and conform to the eight criteria. This framework allows the assessment of aquaculture activities (or any other sector) against these criteria. These criteria would allow for the mindful design and development of future aquaculture activities to deliver NbS (Table 1) inline with Eggermont's typology of "managing ecosystems in very intrusive ways or even creating new ecosystems (e.g., artificial ecosystems with new assemblages of organism)."

When considering the application of these criteria to a highly diverse sector such as aquaculture it becomes evident that some sectors and practices within the industry are easier than others to demonstrate their potential future design as NbS. A systemic attempt to synthesise the way in which aquaculture can augment ES to deliver solutions to societal challenges while augmenting those ES and protecting ecosystem functioning showed that provisioning and regulating (using the Millennium Ecosystem Assessment Framework) were the most commonly addressed services (Weitzman, 2019). In conjunction with this there is clear understanding that the culture of low trophic species (such as bivalve and seaweed culture) have a good potential to augment regulating ES (Alleway et al., 2019) and as such may be the most appropriate to align with the concept of $\mathrm{NbS}$.

\section{CONCLUSION}

The application of the NbS framework to low trophic and integrated aquaculture may allow the unlocking of investment linked to the enhancement of ES such as nutrient reduction. In general those aquaculture operations that are considered to extract inorganic nutrients (seaweed aquaculture) and organic nutrients (bivalve aquaculture; Troell et al., 2009) are more easily 
aligned with the criteria than fed species. But the conscious integration of multiple species groups (both extractive and fed) to meet multiple challenges may also meet the criteria, when balanced so as to provide a net benefit to human well-being and ecosystem functions (Chopin et al., 2012).

\section{AUTHOR CONTRIBUTIONS}

The author confirms being the sole contributor of this work and has approved it for publication.

\section{REFERENCES}

Abhinav, K. A., Collu, M., Benjamins, S., Cai, H., Hughes, A., Jiang, B., et al. (2020). Offshore multi-purpose platforms for a blue growth: a technological, environmental and socio-economic review. Sci. Total Environ. 734:138256. doi: 10.1016/j.scitotenv.2020.138256

Ahmed, N., and Thompson, S. (2019). The blue dimensions of aquaculture: a global synthesis. Sci. Total Environ. 652, 851-861. doi: 10.1016/j.scitotenv.2018.10.163

Alexander, K., and Hughes, A. (2017). A problem shared: technology transfer and development in European integrated multi-trophic aquaculture (IMTA). Aquaculture 473, 13-19. doi: 10.1016/j.aquaculture.2017.01.029

Alleway, H. K., Gillies, C., Bishop, M. J., Gentry, R., Theuerkauf, S. J., Jones, R., et al. (2019). The ecosystem services of marine aquaculture: valuing benefits to people and nature. BioScience 69, 59-68. doi: 10.1093/biosci/biy137

Almenar, J. B., Elliot, T., Rugani, B., Philippe, B., Gutiérrez, T., Sonnemann, G., et al. (2021). Nexus between nature-based solutions, ecosystem services and urban challenges. Land Use Policy 100:104898. doi: 10.1016/j.landusepol.2020. 104898

Bank, W., Economic, U. N. D. O., and Affairs, S. (2017). World Bank 2017. Washington, D.C: World Bank.

Berkes, F., Folke, C., and Colding, J. (2000). Linking Social and Ecological Systems: Management Practices and Social Mechanisms for Building Resilience. Cambridge: Cambridge University Press.

Bohnes, F. A., Hauschild, M. Z., Schlundt, J., and Laurent, A. (2019). Life cycle assessments of aquaculture systems: a critical review of reported findings with recommendations for policy and system development. Rev. Aquac. 11, 1061-1079. doi: 10.1111/raq.12280

Brugère, C., Aguilar-Manjarrez, J., Beveridge, M. C., and Soto, D. (2019). The ecosystem approach to aquaculture 10 years on-a critical review and consideration of its future role in blue growth. Rev. Aquac. 11, 493-514. doi: $10.1111 / \mathrm{raq} .12242$

Bush, S. R., Oosterveer, P., Bottema, M., Meuwissen, M., Mey, Y., Chamsai, S., et al. (2019). Inclusive environmental performance through 'beyondfarm'aquaculture governance. Curr. Opin. Environ. Sustain. 41, 49-55. doi: 10.1016/j.cosust.2019.09.013

Campbell, L. M., Fairbanks, L., Murray, G., Stoll, J. S., D’Anna, L., and Bingham, J. (2021). From blue economy to blue communities: reorienting aquaculture expansion for community wellbeing. Mar. Policy 124:104361. doi: 10.1016/j. marpol.2020.104361

Cervigni, R., and Scandizzo, P. L. (2017). The Ocean Economy in Mauritius. Washington, D.C: World Bank.

Chopin, T., Cooper, J. A., Reid, G., Cross, S., and Moore, C. (2012). Openwater integrated multi-trophic aquaculture: environmental biomitigation and economic diversification of fed aquaculture by extractive aquaculture. Rev. Aquac. 4, 209-220. doi: 10.1111/j.1753-5131.2012.01074.x

Cohen-Shacham, E., Andrade, A., Dalton, J., Dudley, N., Jones, M., Kumar, C., et al. (2019). Core principles for successfully implementing and upscaling naturebased solutions. Environ. Sci. Policy 98, 20-29. doi: 10.1016/j.envsci.2019.04. 014

Cohen-Shacham, E., Walters, G., Janzen, C., and Maginnis, S. (2016). Nature-Based Solutions to Address Global Societal Challenges. Gland: International Union for Conservation of Nature.

\section{FUNDING}

This work was funded through the AquaVitae project under the European Union's Research and Innovation Programme, Grant No. 818173.

\section{ACKNOWLEDGMENTS}

The author would like to thank the reviewers for their valuable insight and comments, and also Prof. Paul Tett for his time in discussing these ideas.

Craig, R. K. (2019). Fostering adaptive marine aquaculture through procedural innovation in marine spatial planning. Mar. Policy 110:103555. doi: 10.1016/ j.marpol.2019.103555

Doremus, H., Andreen, W. L., Camacho, A., Farber, D. A., Glicksman, R. L., Goble, D., et al. (2011). Making Good Use of Adaptive Management. Washington, DC: Center for Progressive Reform White Paper.

Du Pisani, J. A. (2006). Sustainable development-historical roots of the concept. Environ. Sci. 3, 83-96. doi: 10.1080/15693430600688831

Eggermont, H., Balian, E. V., Azevedo, M. N., Beumer, V., Brodin, T., Claudet, J., et al. (2015). Nature-based solutions: new influence for environmental management and research in Europe. GAIA Ecol. Perspect. Sci. Soc. 24, 243-248.

European Commission (2020). The EU Blue Economy Report 2020. Luxembourg: European Commission.

Fang, J., Zhang, J., Xiao, T., Huang, D., and Liu, S. (2016). Integrated multitrophic aquaculture (IMTA) in Sanggou Bay, China. Aquac. Environ. Interact. 8, 201-205. doi: 10.3354/aei00179

FAO (2005). Putting into Practice the Ecosystem Approach to Fisheries. Rome: Food and Agriculture Organization.

FAO (2020). The State of World Fisheries and Aquaculture 2020. Sustainability in Action. Rome: Food and Agriculture Organization.

Froehlich, H. E., Gentry, R. R., and Halpern, B. S. (2017). Conservation aquaculture: shifting the narrative and paradigm of aquaculture's role in resource management. Biol. Conserv. 215, 162-168. doi: 10.1016/j.biocon.2017. 09.012

Galappaththi, E. K., Ichien, S. T., Hyman, A. A., Aubrac, C. J., and Ford, J. D. (2020). Climate change adaptation in aquaculture. Rev. Aquac. 12, 2160-2176.

Gentry, R. R., Alleway, H. K., Bishop, M., Gillies, C., Waters, T. J., and Jones, R. C. (2020). Exploring the potential for marine aquaculture to contribute to ecosystem services. Rev. Aquac. 12, 499-512. doi: 10.1111/raq.12328

Gimpel, A., Stelzenmüller, V., Töpsch, S., Galparsoro, I., Gubbins, M., Miller, D., et al. (2018). A GIS-based tool for an integrated assessment of spatial planning trade-offs with aquaculture. Sci. Total Environ. 627, 1644-1655. doi: 10.1016/j. scitotenv.2018.01.133

Gopal, N., Hapke, H. M., Kusakabe, K., Rajaratnam, S., and Williams, M. J. (2020). Expanding the Horizons for Women in Fisheries and Aquaculture. Milton Park: Taylor \& Francis.

Graham, A., and D'Andrea, A. (2021). Gender and Human Rights in Coastal Fisheries and Aquaculture: A Comparative Analysis of Legislation in Fiji, Kiribati, Samoa, Solomon Islands, Tonga an d Vanuatu. Noumea: Pacific Community.

Hishamunda, N., Ridler, N., and Martone, E. (2014). "Policy and governance in aquaculture: lessons learned and way forward," in Paper Presented at the FAO Fisheries and Aquaculture Technical Paper, Rome.

Hoegh-Guldberg, O. (2015). Reviving the Ocean Economy: The Case for Action. Gland: WWF International.

Inácio, M., Karnauskaite, D., Mikša, K., Gomes, E., Kalinauskas, M., and Pereira, P. (2020). Nature-Based Solutions to Mitigate Coastal Floods and Associated Socioecological Impacts. Heidelberg: Springer.

IOC/UNESCO, IMO, FAO, and UNDP (2011). A Blueprint for Ocean and Coastal Sustainability. Paris: Intergovernmental Oceanographic Commission.

IUCN (2020). Guidance for using the IUCN Global Standard for Nature-based Solutions. A User-Friendly Framework for the Verification, Design and Scaling 
up of Nature-Based Solutions. Gland: International Union for Conservation of Nature.

Kaminski, A. M., Kruijssen, F., Cole, S. M., Beveridge, M. C. M., Dawson, C., Mohan, C. V., et al. (2020). A review of inclusive business models and their application in aquaculture development. Rev. Aquac. 12, 1881-1902.

Krause, G., Billing, S., Dennis, J., Grant, J., Fanning, L., Filgueira, R., et al. (2020). Visualizing the social in aquaculture: how social dimension components illustrate the effects of aquaculture across geographic scales. Mar. Policy 118:103985. doi: 10.1016/j.marpol.2020.103985

Lacoste, É, McKindsey, C. W., and Archambault, P. (2020). Biodiversityecosystem functioning (BEF) approach to further understanding aquacultureenvironment interactions with application to bivalve culture and benthic ecosystems. Rev. Aquac. 12, 2027-2041. doi: 10.1111/raq.12420

Lebel, L., Garden, P., Luers, A., Manuel-Navarrete, D., and Giap, D. H. (2016). Knowledge and innovation relationships in the shrimp industry in Thailand and Mexico. Proc. Natl Acad. Sci. U.S.A. 113, 4585-4590. doi: 10.1073/pnas. 0900555106

Lester, S. E., Stevens, J. M., Gentry, R. R., Kappel, C. V., Bell, T. W., Costello, C. J., et al. (2018). Marine spatial planning makes room for offshore aquaculture in crowded coastal waters. Nat. Commun. 9:945.

Loiseau, E., Saikku, L., Antikainen, R., Droste, N., Hansjürgens, B., Pitkänen, K., et al. (2016). Green economy and related concepts: an overview. J. Clean. Prod. 139, 361-371. doi: 10.1016/j.jclepro.2016.08.024

MacKinnon, K., and Hickey, V. (2009) Oryx. Cambridge: Cambridge University Press, 43, 13-16. doi: 10.1017/S0030605308431046

MacKinnon, K., Sobrevila, C., and Hickey, V. (2008). Biodiversity, Climate Change, and Adaptation: Nature-Based Solutions from the World Bank portfolio. Washington, DC: World Bank.

Maes, J., and Jacobs, S. (2017). Nature-based solutions for Europe's sustainable development. Conserv. Lett. 10, 121-124. doi: 10.1111/conl.12216

Meadows, D. H., Meadows, D. L., Randers, J., and Behrens, W. W. (1972). The limits to growth. NY. 102:27.

Neori, A., and Nobre, A. M. (2012). Relationship between trophic level and economics in aquaculture. Aquac. Econ. Manag. 16, 40-67. doi: 10.1080/ 13657305.2012 .649046

OECD (2020). Reframing Financing and Investment for a Sustainable Ocean Economy. Paris: Organisation for Economic Co-operation and Development.

Ostrom, E. (2009). A general framework for analyzing sustainability of socialecological systems. Science 325, 419-422. doi: 10.1126/science.1172133

Parker, C. (2009). Position Paper International Union for Conservation of Nature No Time to Lose-Make Full use of Nature-Based Solutions in the Post-2012 Climate Change Regime Recommendations for COP 15. Gland: International Union for Conservation of Nature.

Ponte, S., Kelling, I., Jespersen, K. S., and Kruijssen, F. (2014). The blue revolution in Asia: upgrading and governance in aquaculture value chains. World Dev. 64, 52-64. doi: 10.1016/j.worlddev.2014.05.022

Randone, M., Di Carlo, G., Costantini, M., Tzanetti, T., Haferkamp, D., Portafaix, A., et al. (2017). Reviving the Economy of the Mediterranean Sea: Actions for a Sustainable Future. WWF Mediterranean Marine Initiative. Rome: International Union for Conservation of Nature.

Reid, W. V., Mooney, H. A., Cropper, A., Capistrano, D., Carpenter, S. R., Chopra, K., et al. (2005). Ecosystems and Human Well-Being-Synthesis: A Report of the Millennium Ecosystem Assessment. Washington, DC: Island Press.

REUTERS (2020). ESG Investors Slow to Make Waves in the \$2.5tn Ocean Economy. Available online at: https://www.reutersevents.com/sustainability/ esg-investorsslow-make-waves-25tn-ocean-economy (accessed June 14, 2021).

Rodríguez-Robayo, K. J., and Merino-Perez, L. (2017). Contextualizing context in the analysis of payment for ecosystem services. Ecosyst. Serv. 23, 259-267. doi: 10.1016/j.ecoser.2016.12.006

Seddon, N., Smith, A., Smith, P., Key, I., Chausson, A., Girardin, C., et al. (2021). Getting the message right on nature-based solutions to climate change. Glob. Change Biol. 27, 1518-1546. doi: 10.1111/gcb.15513
Shah, M. A. R., Renaud, F. G., Anderson, C. C., Wild, A., Domeneghetti, A., Polderman, A., et al. (2020). A review of hydro-meteorological hazard, vulnerability, and risk assessment frameworks and indicators in the context of nature-based solutions. Int. Journal Disaster Risk Reduct. 50:101728. doi: 10.1016/j.ijdrr.2020.101728

Sondak, C. F., Ang, P., Beardall, J., Bellgrove, A., Boo, S., Grevo, S., et al. (2017). Carbon dioxide mitigation potential of seaweed aquaculture beds (SABs). J. Appl. Phycol. 29, 2363-2373. doi: 10.1007/s10811-0161022-1

Soto, D., Aguilar-Manjarrez, J., and Hishamunda, N. (2007). "Building an ecosystem approach to aquaculture," in Proceedings of the FAO/Universitat de les Illes Balears Expert Workshop, (Palma de Mallorca: Food and Agriculture Organization).

Sowell, T. (2019). The Vision of the Anointed: Self-Congratulation as a Basis for Social Policy. New York, NY: Hachette.

Suisse, R. I. C. (2020). Investors and the Blue Economy. Luxembourg: Office of the European Union.

Sumaila, U. R., Walsh, M., Hoareau, K., and Cox, A. (2020). Ocean Finance: Financing the Transition to a Sustainable Ocean Economy. Washington, DC: World Resources Institute .

Troell, M., Joyce, A., Chopin, T., Neori, A., Buschmann, A. H., and Fang, J.-G. (2009). Ecological engineering in aquaculture-potential for integrated multitrophic aquaculture (IMTA) in marine offshore systems. Aquaculture 297, 1-9. doi: 10.1016/j.aquaculture.2009.09.010

UNEP (2021). The Rising Tide: Mapping Ocean Finance for a New Decade United Nations Environment - Finance Initiative. Nairobi: United Nations Environment Programme.

Valenti, W. C., Kimpara, J. M., Preto, B. D. L., and Moraes-Valenti, P. (2018). Indicators of sustainability to assess aquaculture systems. Ecol. Indic. 88, 402413. doi: $10.1016 /$ j.ecolind.2017.12.068

Weitzman, J. (2019). Applying the ecosystem services concept to aquaculture: a review of approaches, definitions, and uses. Ecosyst. Serv. 35, 194-206. doi: 10.1016/j.ecoser.2018.12.009

Wenhai, L., Cusack, C., Baker, M., Tao, W., Mingbao, C., Paige, K., et al. (2019). Successful blue economy examples with an emphasis on international perspectives. Front. Mar. Sci. 6:261. doi: 10.3389/fmars.2019.00261

Whisnant, R., and Vandeweerd, V. (2019). Investing in the new blue economy: the changing role of international development organizations in catalyzing private sector investment in support of regional strategic action programmes for the sustainable development of coasts and oceans. J. Ocean Coast. Econ. $6: 8$.

Author Disclaimer: The information contained within the manuscript reflects the views of the author only.

Conflict of Interest: The author declares that the research was conducted in the absence of any commercial or financial relationships that could be construed as a potential conflict of interest.

Publisher's Note: All claims expressed in this article are solely those of the authors and do not necessarily represent those of their affiliated organizations, or those of the publisher, the editors and the reviewers. Any product that may be evaluated in this article, or claim that may be made by its manufacturer, is not guaranteed or endorsed by the publisher.

Copyright (c) 2021 Hughes. This is an open-access article distributed under the terms of the Creative Commons Attribution License (CC BY). The use, distribution or reproduction in other forums is permitted, provided the original author(s) and the copyright owner(s) are credited and that the original publication in this journal is cited, in accordance with accepted academic practice. No use, distribution or reproduction is permitted which does not comply with these terms. 